\title{
Predicting cancer-relevant proteins using an improved molecular similarity ensemble approach
}

\author{
Bin Zhou ${ }^{1,2, *}$, Qi Sun ${ }^{1,2, *}$, De-Xin Kong ${ }^{1,2}$ \\ ${ }^{1}$ State Key Laboratory of Agricultural Microbiology, Huazhong Agricultural University, Wuhan 430070, China \\ ${ }^{2}$ Agricultural Bioinformatics Key Laboratory of Hubei Province, College of Informatics, Huazhong Agricultural University, \\ Wuhan 430070, China \\ "These authors contributed equally to this work
}

Correspondence to: De-Xin Kong, email: dxkong@mail.hzau.edu.cn.

Keywords: chemoinformatics, cancer, cell line, drug development, similarity ensemble approach

Received: October 26, 2015

Accepted: March 28, 2016

Published: April 13, 2016

\section{ABSTRACT}

In this study, we proposed an improved algorithm for identifying proteins relevant to cancer. The algorithm was named two-layer molecular similarity ensemble approach (TL-SEA). We applied TL-SEA to analyzing the correlation between anticancer compounds (against cell lines K562, MCF7 and A549) and active compounds against separate target proteins listed in BindingDB. Several associations between cancer types and related proteins were revealed using this chemoinformatics approach. An analysis of the literature showed that 26 of $\mathbf{3 5}$ predicted proteins were correlated with cancer cell proliferation, apoptosis or differentiation. Additionally, interactions between proteins in BindingDB and anticancer chemicals were also predicted. We discuss the roles of the most important predicted proteins in cancer biology and conclude that TL-SEA could be a useful tool for inferring novel proteins involved in cancer and revealing underlying molecular mechanisms.

\section{INTRODUCTION}

In 1990, approximately 6 million people died of cancer globally, while in 2010 the number had risen to about 8 million [1]. Moreover, the incidence of cancer is increasing rapidly [2]. Current cancer treatments include surgical therapy, radiation therapy, and chemotherapy; however, these treatments also damage normal tissues. Many researchers are focused on developing targeted molecular therapies that specifically damage tumor tissues with little damage to normal tissue [3]. Comprehensive understanding of the molecular mechanisms underlying cancer is necessary for designing efficacious drugs.

The molecular mechanisms of cancer development are very complicated, and include lasting proliferation, malfunction of cell death programs, induction of angiogenesis, metastasis of cancer cells, changes of cellular energy metabolism, and evasion of immune destruction [4]. This complexity, along with a lack of reliable methods for the large-scale identification of cancer-related proteins, causes cancer progression to remain a puzzle and greatly hampers the development of effective therapies. Traditional experimental methods are not suitable for the large-scale identification of cancer-related proteins because they are both timeconsuming and inefficient. Computational methods rely on systematic comparisons between the genomes of cancer cells and normal cells, using correlation analysis to search for mutated genes associated with tumorigenesis [5]. However, many of these methods only utilize DNA sequence information [6-8], and overlook protein information that is more closely related to biological pathways and phenotype.

In 2015, Chien-Hung Huang et al. developed a prediction model of cancer proteins based on proteomic data [9]. They demonstrated the accuracy of this method on two independent datasets of lung cancer and lung cancer microarray. Their prediction achieved hit ratios of $89.4 \%$ and $72.8 \%$, respectively. Two other groups predicted cancer-related proteins as new drug targets for cancer treatment with network analyses $[10,11]$. These predictions were mainly based on protein interaction networks, protein sequences, or motif information. Importantly, no cancer-related small-molecule activity data were considered in these studies. Taking into consideration the limitations of these approaches, there is a great demand for new methods to infer key proteins in cancer. 
With the open-source drug discovery campaign, massive bioactivity data have been accumulated using assays ranging from phenotypes to enzymes. For example, the National Cancer Institute (NCI) has launched many programs for screening compounds against cancer cell lines and has acquired a large list of active anticancer chemicals [12]. On the other hand, BindingDB catalogues an enormous number of active compounds that act on various proteins [13].

Chemoinformatics approaches can be applied to compare anticancer compounds from the NCI database and bioactive compounds against different proteins from BindingDB, and infer proteins that are involved in the genesis and proliferation of cancer cells. The underlying assumption, named similarity principle or general neighborhood behavior, is that structurally similar molecules are likely to possess similar biological activities [14-18]. Provided that anticancer chemical a is very akin to chemical $b$, which is active against a protein, it is possible that a can also change the state of this protein and the anticancer effects of a depend on the same protein. The more similar molecule pairs are found, the more correct is the assumption. Therefore, the association between these proteins and cancer development can be confirmed through a systematic statistics probability analysis on massive activity data about the phenotype and the proteins.

However, the similarity between the ligand set of a protein and that of a phenotype is very weak and proteinphenotype relationships can be inferred only with very careful statistical analysis. In 2007, Michael J Keiser et al. proposed a Similarity Ensemble Approach (SEA) to infer relationships among receptors [19]. The SEA algorithm can be applied to two compound sets at the same level $[20,21]$, but is not suitable for systems at two different levels, such as active compounds against cancer cell lines and against proteins. Therefore, in this work, we proposed a modified association algorithm, named two-layer SEA (TL-SEA), and applied the algorithm to the analysis of the activity data from the NCI database and BindingDB. Three cell lines, K562, MCF7 and A549 were used as example systems. The K562 cell line was derived from the blastic phase of chronic myelogenous leukemia. It also has some characteristics of chronic leukemia and acute leukemia [22]. MCF7 and A549 were derived from human breast cancer and human lung cancer, respectively. Using TLSEA, we attempted to infer which proteins play roles in the genesis and proliferation of these cancer cells.

\section{RESULTS}

\section{Prediction of cancer-related proteins}

Important cancer-related proteins were successfully predicted with our algorithm (TL-SEA) based on the existing active compounds against the three cancer cell lines and BindingDB proteins. Proteins with a smaller association value (AS score) were more likely to impact on the development of cancer. In this study, we selected the proteins with AS scores smaller than 0.03 for further analysis, resulting in a total of 35 cancer-related proteins $(31,35$, and 28 proteins for K562, MCF7 and A549 cell lines, respectively; Table 1). There were 25 common proteins in the three systems. Most of the predicted proteins were human proteins or their close homologs except luciferin 4-monooxygenase of firefly. According to previously published literature, 26 of the 35 proteins are relevant to the proliferation, apoptosis, or differentiation of cancer cells. The references are listed in the last column of Table 1.

Among the 26 proteins, melatonin receptor type 1B occurs twice. One of them is from chicken (ranked first in all the cell lines) and the other one from human (ranked 22nd, 24th, 22nd in the 3 cell lines, respectively). BLASTP showed that these two proteins were very similar with E-Value $=7 \mathrm{e}^{-150}$, sequence identity $=71 \%$ and sequence cover $=100 \%$. Melatonin receptors play an important role in cancer development [23-27], and have anticancer functions through binding with melatonin [26]. Melatonin is involved in redox processes of cells, augments natural killer cell activity, stimulates cytokine production (IL-2 and IL-6), and protects hematopoietic precursors from the toxic effect of chemotherapy and radiotherapy [27]. Studies revealed that breast cancer cell differentiation is regulated by the MT-1 signaling pathway $[28,29]$, while the anticancer function of melatonin is mediated by MT-1 receptor and G protein-coupled signal transduction in liver cancer cells [30]. Clinical data also showed high MT-1 expression is associated with cancer resistance in people with lower melatonin levels [31]. Melatonin may also protect against gastric cancer in mice by up-regulation of membrane receptor MT-1 and MT-2 expression [32].

The second and the third proteins in the predicted list are tubulin beta- 1 chain and tissue factor (TF). Tubulin beta- 1 chain is the primary component of microtubules. Microtubules play a key role in the process of mitosis [33], which is necessary for cancer cell proliferation. Thus, disruption of cell mitosis can block the increase in cancer cells. As early as 2004, there was research on microtubules as targets for anticancer drugs [34]. Similarly, TF expression in the cell surface accelerates tumor progression [35, 36]. TF accelerates malignant tumor growth, invasion, and metastasis mainly by promoting vascular endothelial growth factor (VEGF) release to regulate tumor cell angiogenesis [37]. Interestingly, the VEGF receptor 2 is ranked 23rd in the predicted protein list. Reduced $\mathrm{TF}$ expression can decrease cancer cell growth, and selective reduction of $\mathrm{TF}$ expression with mRNAi in colorectal cancer cells reduced tumor growth in mice [38]. These results have been replicated in vitro [39], and higher TF expression was found in primary carcinoma of the rectum, breast cancer and pancreatic cancer. Thus, 
Table 1: List of the predicted cancer-related proteins

\begin{tabular}{|c|c|c|c|c|c|c|}
\hline \multirow{2}{*}{ Protein ID* } & \multirow{2}{*}{ Protein name } & \multirow{2}{*}{ Source } & \multicolumn{3}{|c|}{ AS score (rank) } & \multirow{2}{*}{ Reference } \\
\hline & & & K562 & MCF7 & A549 & \\
\hline P51050 & Melatonin receptor type $1 \mathrm{~B}$ & Chicken & $0.0021(1)$ & $0.0025(1)$ & $0.0025(1)$ & {$[53]$} \\
\hline Q9H4B7 & Tubulin beta- 1 chain & Human & $0.0062(2)$ & $0.0064(3)$ & $0.0083(4)$ & {$[54]$} \\
\hline P13726 & Tissue factor & Human & $0.0065(3)$ & $0.0077(6)$ & $0.0080(3)$ & {$[55]$} \\
\hline P25106 & Atypical chemokine receptor 3 & Human & $0.0066(4)$ & $0.0067(4)$ & $0.0093(6)$ & {$[56]$} \\
\hline Q8CA95 & $\begin{array}{l}\text { cAMP and cAMP- } \\
\text { inhibited cGMP } 3^{\prime}, 5^{\prime} \text {-cyclic } \\
\text { phosphodiesterase } 10 \mathrm{~A}\end{array}$ & Mouse & $0.0083(5)$ & $0.0075(5)$ & $0.0090(5)$ & \\
\hline P35355 & Prostaglandin $\mathrm{G} / \mathrm{H}$ synthase 2 & Rat & $0.0093(6)$ & $0.0084(7)$ & $0.0103(7)$ & {$[57]$} \\
\hline P60842 & Eukaryotic initiation factor $4 \mathrm{~A}-\mathrm{I}$ & Human & $0.0103(7)$ & $0.0102(8)$ & $0.0137(9)$ & {$[58]$} \\
\hline P34960 & Macrophage metalloelastase & Mouse & $0.0125(8)$ & $0.0118(9)$ & $0.0149(10)$ & [59] \\
\hline Q6B856 & Tubulin beta-2B chain & Bovine & $0.0139(9)$ & $0.0124(10)$ & $0.0155(11)$ & {$[60]$} \\
\hline P30549 & Substance-K receptor & Mouse & $0.0149(10)$ & $0.0143(13)$ & $0.0175(13)$ & {$[61]$} \\
\hline P06795 & Multidrug resistance protein 1B & Mouse & $0.0154(11)$ & $0.0137(12)$ & $0.0176(14)$ & {$[62]$} \\
\hline P52895 & $\begin{array}{l}\text { Aldo-keto reductase family } \\
1 \text { member C2 }\end{array}$ & Human & $0.0160(12)$ & $0.0191(19)$ & $0.0187(15)$ & {$[63]$} \\
\hline Q63008 & Sodium/iodide cotransporter & Rat & $0.0172(13)$ & $0.0168(15)$ & $0.0208(19)$ & {$[64]$} \\
\hline P08575 & $\begin{array}{l}\text { Receptor-type tyrosine-protein } \\
\text { phosphatase C }\end{array}$ & Human & $0.0177(14)$ & $0.0216(22)$ & $0.0189(16)$ & \\
\hline Q9QUK6 & Toll-like receptor 4 & Mouse & $0.0180(15)$ & $0.0201(20)$ & $0.0286(28)$ & {$[65]$} \\
\hline P41586 & $\begin{array}{l}\text { Pituitary adenylate cyclase- } \\
\text { activating polypeptide type I } \\
\text { receptor }\end{array}$ & Human & $0.0188(16)$ & $0.0176(17)$ & $0.0171(12)$ & {$[66]$} \\
\hline O02747 & Aryl hydrocarbon receptor & Rabbit & $0.0198(17)$ & $0.0176(16)$ & $0.0202(17)$ & {$[67]$} \\
\hline 043526 & $\begin{array}{l}\text { Potassium voltage-gated channel } \\
\text { subfamily KQT member } 2\end{array}$ & Human & $0.0226(18)$ & $0.0261(28)$ & $0.0267(24)$ & {$[68]$} \\
\hline Q12791 & $\begin{array}{l}\text { Calcium-activated potassium } \\
\text { channel subunit alpha-1 }\end{array}$ & Human & $0.0235(19)$ & $0.0298(35)$ & $0.0253(23)$ & [69] \\
\hline Q27757 & Luciferin 4-monooxygenase & Firefly & $0.0239(20)$ & $0.0153(14)$ & $0.0241(20)$ & \\
\hline Q8R2Y0 & $\begin{array}{l}\text { Monoacylglycerol lipase } \\
\text { ABHD6 }\end{array}$ & Mouse & $0.0245(21)$ & $0.0272(29)$ & - & {$[70]$} \\
\hline P49286 & Melatonin receptor type $1 \mathrm{~B}$ & Human & $0.0247(22)$ & $0.0245(24)$ & $0.0247(22)$ & {$[53]$} \\
\hline P35968 & $\begin{array}{l}\text { Vascular endothelial growth } \\
\text { factor receptor } 2\end{array}$ & Human & $0.0248(23)$ & $0.0179(18)$ & $0.0204(18)$ & {$[71]$} \\
\hline P51787 & $\begin{array}{l}\text { Potassium voltage-gated channel } \\
\text { subfamily KQT member } 1\end{array}$ & Human & $0.0268(24)$ & $0.0216(21)$ & $0.0244(21)$ & \\
\hline P23097 & Collagenase 3 & Rat & $0.0269(25)$ & $0.0281(31)$ & - & {$[72]$} \\
\hline P48039 & Melatonin receptor type $1 \mathrm{~A}$ & Human & $0.0270(26)$ & $0.0260(27)$ & $0.0259(24)$ & {$[53]$} \\
\hline Q8TCW9 & Prokineticin receptor 1 & Human & $0.0278(27)$ & $0.0252(26)$ & - & {$[73]$} \\
\hline Q13370 & $\begin{array}{l}\text { cGMP-inhibited 3', 5'-cyclic } \\
\text { phosphodiesterase B }\end{array}$ & Human & $0.0292(28)$ & $0.0223(23)$ & $0.0280(27)$ & \\
\hline P48145 & $\begin{array}{l}\text { Neuropeptides } \mathrm{B} / \mathrm{W} \text { receptor } \\
\text { type } 1\end{array}$ & Human & $0.0294(29)$ & $0.0284(33)$ & - & {$[74]$} \\
\hline O76074 & $\begin{array}{l}\text { cGMP-specific } 3^{\prime}, 5^{\prime} \text {-cyclic } \\
\text { phosphodiesterase }\end{array}$ & Human & $0.0296(30)$ & $0.0282(32)$ & - & {$[75]$} \\
\hline
\end{tabular}




\begin{tabular}{|l|l|c|c|c|c|c|}
\hline P48974 & Vasopressin V1b receptor & Rat & $0.0299(31)$ & $0.0293(34)$ & - & \\
\hline Q61614 & Endothelin-1 receptor & Mouse & - & $0.0033(2)$ & $0.0043(2)$ & \\
\hline $\mathbf{P 2 3 9 0 7}$ & Major prion protein & Sheep & - & $0.0134(11)$ & $0.0122(8)$ & \\
\hline $\mathbf{O 4 3 6 0 3}$ & Galanin receptor type 2 & Human & - & $0.0251(25)$ & $0.0272(26)$ & {$[76]$} \\
\hline Q13698 & $\begin{array}{l}\text { Voltage-dependent L-type } \\
\text { calcium channel subunit alpha- } \\
\text { 1S }\end{array}$ & Human & - & $0.0275(30)$ & - & \\
\hline
\end{tabular}

The list was sorted by K562 significance (AS score), and then by MCF7. References regarding to the proteins related to proliferation, apoptosis, or differentiation of cancer cells were listed in the last column.

"Uniprot ID of the proteins [77].

- AS score larger than 0.03 .

$\mathrm{TF}$ expression is related to the invasiveness of cancer [40], and multiple experimental models have demonstrated that increasing TF expression promotes tumor growth [41].

For those proteins without direct evidence regarding their involvement in cancer development, there is a great chance that they also play important roles in cancer-related cellular pathways. Of course, this hypothesis remains to be confirmed with further studies. We analyzed protein Q8CA95 (cAMP and cAMP-inhibited cGMP 3',5'-cyclic phosphodiesterase $10 \mathrm{~A}$ ), which is ranked 5 th in all the predicted proteins and first in the proteins without direct proof in the literature. The protein hydrolyzes both cAMP and cGMP, regulating the intracellular concentration of cyclic nucleotides in the striatum [42]. As a target for signal transduction regulation, it has not been reported to have anticancer effects; however, cAMP mediates the translation of cancer cells into healthy cells $[43,44]$.

In our algorithm, we needed to calculate the significance twice, $P_{\mathrm{z}}$ and $P_{\mathrm{O}}$, for the anticancer compounds-protein association (initial score, $I$ ) and the cell line-protein association (original score, $P_{O}$ ). Because $I$ was summed at different length $(m$, number of active compounds against a specific protein), it was translated into comparable $Z$ score with formula 4 . The constants $(a, b, k)$ were obtained by fitting the initial score and the number of active compounds with formulae 2 and 3 (Figure 1). The results showed a linear correlation between the initial score $I$ and compound number $m$, indicating the feasibility of the SEA algorithm in such a system. As mentioned in the methods section, it is unnecessary to standardize the original score, $P_{O}$.

\section{Analysis of chemical-protein matrices}

In the process of inferring cancer-related proteins, three anticancer compounds $v s$ BindingDB proteins association matrices $\left(P_{\mathrm{Z}}\right)$ emerged. The matrices contained the significant scores $\left(P_{\mathrm{Z}}\right)$ between the active chemicals targeting the cancer cell lines and the BindingDB proteins. $P_{\mathrm{Z}}$ can be used to deduce whether a compound can interact with a protein. Smaller $P_{\mathrm{z}}$ indicated higher possibility of interaction. By retaining the matrix elements with $P_{Z}$ less than 0.0001 , the matrices were translated into three networks as shown in Figure 2 and Supplementary Figure S1. The nodes in the networks represent proteins or chemicals, while the edges denote their association. The three networks are presented with the same layout. The position of the nodes was optimized with forces according to the reciprocal of the $P_{\mathrm{Z}}$. For nodes that were missed in the cell lines, they were fade out to gray. The other nodes were highlighted with distinguishable colors. Through this way, the differences between the cell lines can be visually analyzed. For example, the major prion protein (node P23097, highlighted with the red rectangle in Figure 2A) did not existed in K562 but existed in other two cell lines. Experimental studies showed that the overexpression of P23097 failed to protect DNA fragmentation in leukemia cancer cell line but it converted TNF-sensitive cells into TNF-resistant cells in MCF7 breast cancer cell line [45-46]. Moreover, the expression of major prion protein were associated with increased lung colonization [47]. These results are consistent with our predictions.

Some of the predicted interactions in Figure 2 were reported earlier and truly existed. For example, the $P_{\mathrm{Z}}$ score between anticancer compound thapsia villosa (NCI_ID 299934) and sarcoplasmic/endoplasmic reticulum calcium ATPase 1 (Uniprot_ID P04191, SERCA 1) was $1.500 \times 10^{-7}$, ranking first in MCF7 dataset (see Supplementary information Table S2). This compound is indeed a potential inhibitor of the SERCA pump [48]. In addition, the $P_{\mathrm{Z}}$ score between compound GW805758X (NCI_ID 756364) and protein O14920 (inhibitor of nuclear factor kappa-B kinase subunit beta) was $1.015 \times 10^{-4}$. Through database searching, this interaction can be found in ChEMBL (http://ebi.ac.uk/ chembl, ChEMBL Assay ID: CHEMBL2007663).

We analyzed the proteins linked to more than 15 compounds in the three networks (Table 2). Protein Q61614 (Endothelin-1 receptor) linked to 59 compounds in the MCF7 dataset, ranked first in all the proteins. The AS score $\left(P_{\mathrm{O}}\right)$ between this protein and MCF7 is 0.0033 , indicating that this protein is a potential target for MCF7 cells. Kusuhara M et al. found that breast cancer cells can release Endothelin-1 [49]. The binding of Endothelin-1 (ET-1) to ET-1 receptor can stimulate growth of breast cancer cells by autocrine and paracrine signaling, and 
increased expression of ET-1, Endothelin A receptor (ETAR), and Endothelin B receptor (ETBR) in breast cancer patients lowers disease-free survival time and overall survival [50].

Among the 27 proteins in Table 2, only 4 proteins (Q9H4B7, P41586, Q61614 and O02747) were associated with the cell lines with an AS score $\left(P_{\mathrm{o}}\right)$ less than 0.03 . This result was caused by different thresholds used in the original score calculation process and in Figure 2, which illustrates the protein-compound interactions with a visual network. Only connections with $P \mathrm{z}<0.0001$ were retained to simplify the networks. For $P_{\mathrm{O}}$ calculation, more information was needed for association analysis. Thus, we used a threshold of $P \mathrm{z}<0.01$. If the threshold of the connections was changed to $P \mathrm{z}<0.001$, all the 11 proteins with more than 70 connections were associated with the cell lines $\left(P_{\mathrm{O}}<0.03\right)$. The results proved the capability of our algorithm for deep data mining. That is, the association score was deduced with large numbers of weak similarities between the active compounds of the cell lines and the proteins instead of fewer but stronger similarities.

We also analyzed two sub-networks (Figure 2C', $2 \mathrm{C}$ ") extracted from the interaction network of MCF7 active compounds and the proteins (Figure 2C). Figure 2C' shows the predicted interactions between a MCF7 active compound (NCI_ID 727680) and 7 proteins, while Figure $2 \mathrm{C}$ " shows the interactions between a BindingDB protein (Uniprot_ID P05227) and 17 anticancer compounds for the MCF7 cell line. Detailed information about the subnetworks, including proteins, compounds and $P_{\mathrm{Z}}$ between them can be found in Supplementary Table S1. Full information on $P_{\mathrm{Z}}<0.0001$ data in MCF7 can be found in Table S2. We randomly selected 4 active compounds (NCI ID 353, 8591, 695939, 743862) from these 17 anticancer compounds in Figure 2C" and calculated the similarity between these NCI compounds and the active compounds against the BindingDB proteins (Uniprot_ID P05227). Most of the similarities were around 0.2 , except very few high similarity scores (Supplementary Table S3). This result is consistent with Keiser's research, which found that for most ligand pairs the similarity was low, ranging from 0.2 to 0.3 [19]. This result also indicates the necessity to use strict statistical algorithms in such systems and confirms our previous deductions.

\section{DISCUSSION}

Prior methods for large-scale identification of cancer-related genes or proteins were primarily based on the discrepancies between the genomes of cancer cells and normal cells, and rarely took into consideration ligandprotein interactions. Our research employed the activity data of the chemicals targeting proteins or cancer cells in existing databases, enabling us to analyze the mechanisms underlying tumorigenesis from the perspective of chemistry. A chemoinformatics approach (TL-SEA) was
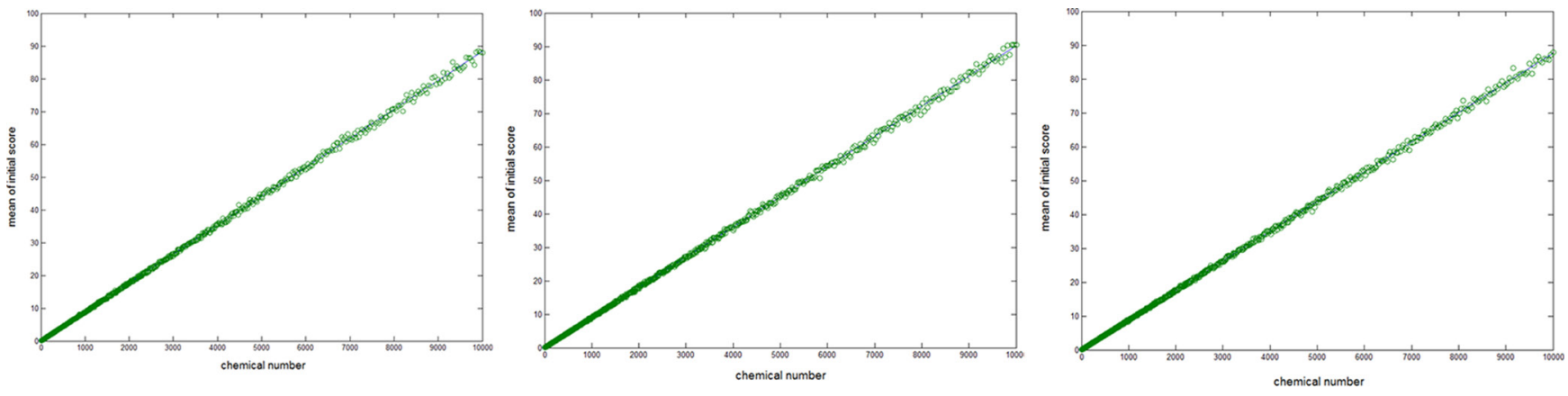

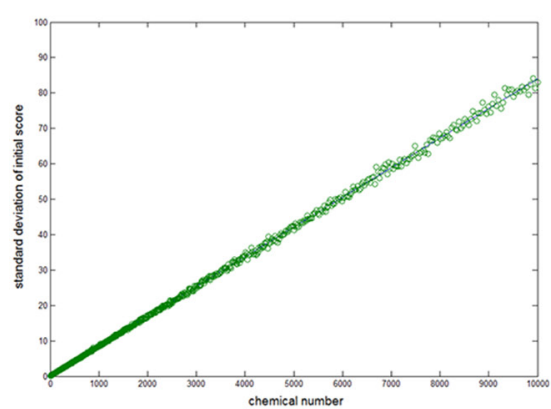

A. K562

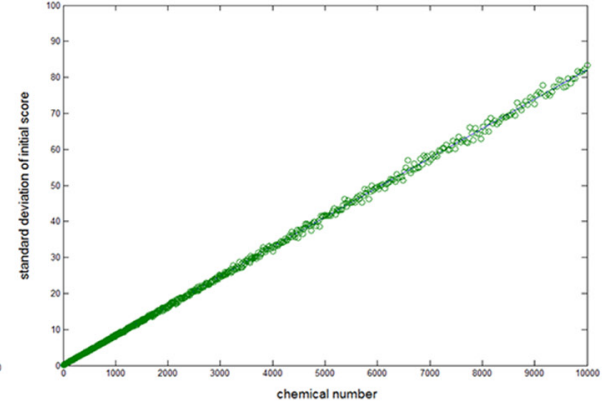

B. MCF7

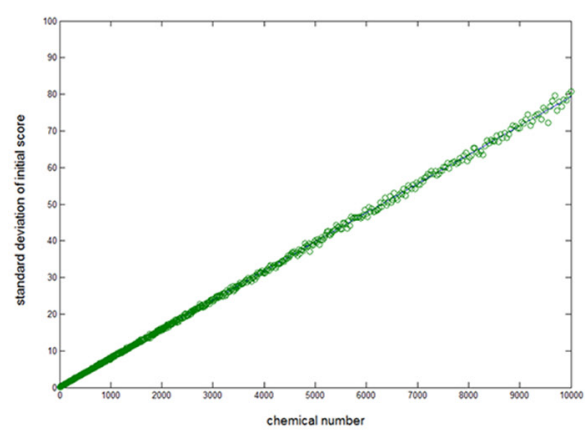

C. A549

Figure 1: Scatter graph of the mean value (top) and standard deviation (bottom) of random initial score (I) with different sampling lengths ( $\boldsymbol{m}$, horizontal axis). (A) For K562 dataset. Fitting with formulae 2, 3, constant parameters were estimated ( $a=0.0088$, $b=0.9950, k=0.0088$ ). (B) For MCF7 dataset, $a=0.0086, b=0.9952, k=0.0090$. (C) For A549 dataset, $a=0.0083, b=0.9969, k=0.0089$. 
Table 2: List of the proteins linked to more than 15 anticancer compounds according to $P_{\mathrm{z}}<0.0001$

\begin{tabular}{|c|c|c|c|}
\hline \multirow[t]{2}{*}{ Protein_ID } & \multicolumn{3}{|c|}{ Number of linked compounds } \\
\hline & K562 & MCF7 & A549 \\
\hline Q61614 & - & $59^{*}$ & $58^{*}$ \\
\hline Q9H4B7 & $30^{*}$ & $27^{*}$ & $32^{*}$ \\
\hline P41586 & $17^{*}$ & $20^{*}$ & $25^{*}$ \\
\hline P07382 & 31 & 31 & 45 \\
\hline P00378 & 30 & 28 & 42 \\
\hline P11387 & 29 & - & - \\
\hline $\mathrm{P} 00375$ & 22 & 25 & 26 \\
\hline P49892 & 21 & 40 & 31 \\
\hline Q6Y1R5 & 21 & 41 & 31 \\
\hline P07900_P08238 & 18 & 15 & - \\
\hline P22102 & 18 & 22 & 24 \\
\hline P34970 & 18 & 37 & 28 \\
\hline Q8TEK3 & 18 & 40 & 28 \\
\hline O02747 & $17^{*}$ & - & $21^{*}$ \\
\hline Q05932 & 17 & 23 & 25 \\
\hline P17707 & - & 44 & 35 \\
\hline O02667 & - & 31 & 22 \\
\hline P23526 & - & 26 & 23 \\
\hline P05227 & - & 19 & 22 \\
\hline P15328 & - & 18 & 20 \\
\hline P28647 & - & 18 & - \\
\hline O00142 & - & 15 & - \\
\hline $\mathrm{P} 41148$ & - & 15 & - \\
\hline Q62645 & - & 15 & 17 \\
\hline P48544 & - & - & 20 \\
\hline P48549 & - & - & 19 \\
\hline Q01782 & - & - & 15 \\
\hline
\end{tabular}

- with less than 15 linked compounds.

"predicted as a cancer related protein.

proposed to compare anticancer compounds with active chemicals binding to a particular protein target. By this means, possible associations between cancer cell lines and proteins were predicted if the two groups of chemicals showed similarity. Literature searches showed that most of the high-ranked proteins were related to proliferation, apoptosis, or differentiation of cancer cells.

Additionally, a chemical-protein interaction matrix was produced, which can help explain the mechanism of the anticancer drugs and also boost the repurposing of anticancer drugs to other fields. In fact, the drugs active against the predicted proteins are also potential active compounds against cancer. This can be quantitatively measured using the TL-SEA algorithm in reverse, to calculate the association between active compounds against the predicted protein targets and NCI cell lines. The above results confirmed the effectiveness of our algorithm. Of course, further laboratory experiments are needed to validate the predicted associations/interactions. Pathway analysis and systems biology simulation can also be performed to interpret the roles of the proteins in tumorigenesis.

The applications of this chemoinformatics approach can be expanded to elucidate the molecular mechanisms of other diseases. For instance, by comparing the active compounds against a bacterium with those targeting a variety of proteins, it is possible to deduce important proteins for the growth of this bacterium. The primary mission in the post-genomic era is to illuminate the relationships among genes, proteins, diseases, pathways and chemicals at an -omics level. It is impossible to finish this 
work using traditional methods. Currently, a large number of small molecule activity data are becoming available to the public, such as ChEMBL and Pubchem [51, 52]. These datasets include the results of high throughput screening at the molecular level and all kinds of phenotypic activity. The relationship between the phenotypes (diseases) and proteins can be inferred using the TL-SEA algorithm proposed here.

Compared with traditional approaches, our approach is economically feasible and fast, and therefore suitable for rapid preliminary screening before further validation. Compared with conventional genome correlation analysis, TL-SEA utilizes the activity data directly, reflecting protein function in the organism. Thus, the results of TL-SEA can be interpreted more easily with pathway analysis. However, the limitations of this approach should not be ignored. The method relies on the activity data of small molecules and only applies to the diseases or proteins whose active molecules are known.

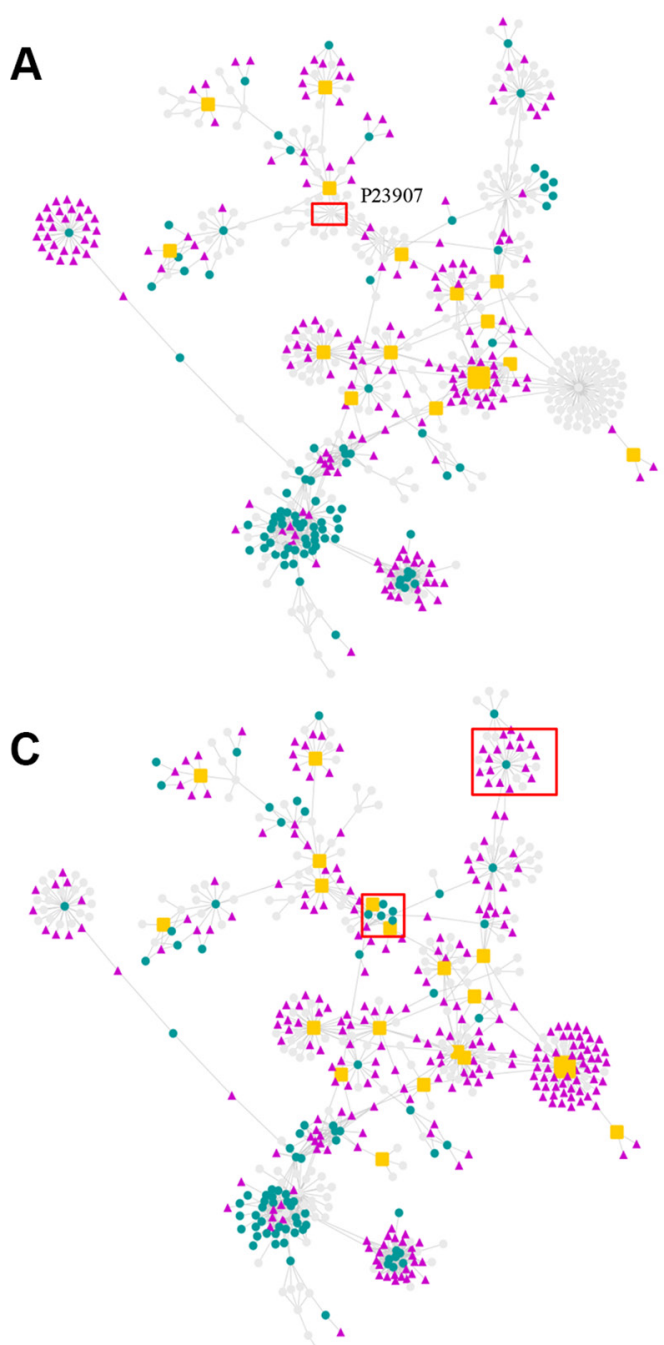

\section{MATERIALS AND METHODS}

\section{General study protocol}

The overall protocol of this study is illustrated in Figure 3. Activity data and structures of small molecules against cancer cell lines and against a variety of proteins were collected from the NCI database and BindingDB. Physicochemical properties and activity thresholds were used to filter off inactive or non-druglike compounds. Then the similarity matrix (target similarity matrix) formed by these two groups of active compounds was calculated with ECFP_ 4 molecular fingerprint and the Tanimoto coefficient. At the same time, large numbers of chemicals satisfying aforementioned physicochemical properties were randomly sampled from BindingDB. The similarity matrix (random similarity matrix) formed by these random BindingDB chemicals and the NCI active compounds of the corresponding

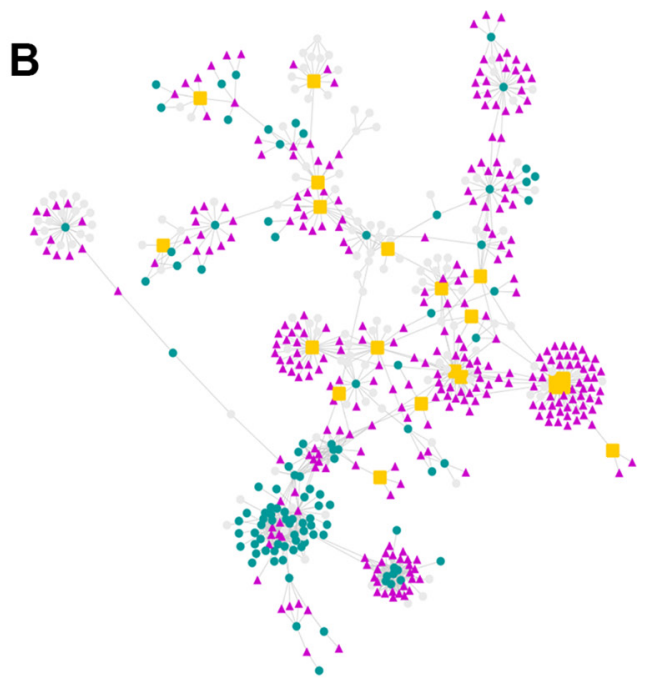

C'

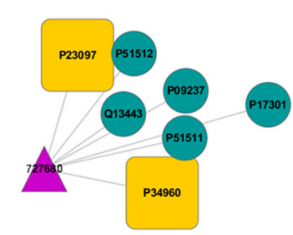

C"

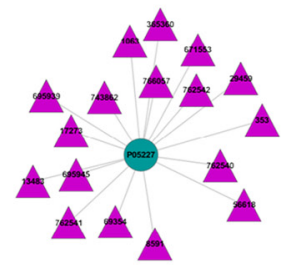

Figure 2: Chemical-protein association networks. The NCI compounds are represented with triangle nodes. Proteins are denoted with round nodes. Among the proteins, the important ones are denoted as orange squares. (A) Main network for blastic phase of chronic myelogenous leukemia (K562) cell line active compounds and proteins. Gray nodes denote that it does not appear in this system. (B) Main network for Non Small Cell Lung cancer (A549) cell line. (C) Main network for breast cancer (MCF7) cell line. C') and C") are two sub-networks extracted from the MCF7 network. See text for details. 
cell line was also calculated in the same manner. Finally, the TL-SEA algorithm was employed to compare the target similarity matrix with the random similarity matrix, and therefore give the association score (AS) between each protein and the cell line. The AS score was used to infer whether a given protein plays a role in the growth of cancer cells. Details about the association algorithm are described below.

\section{NCI database}

Activity and structural data of cancer cell line inhibitors were downloaded from NCI website (https://wiki. nci.nih.gov/display/NCIDTPdata/Chemical+Data). NCI database uses $\mathrm{GI}_{50}$ (growth inhibition of 50\%) as an endpoint, which is the drug concentration giving a $50 \%$ reduction in the cancer cell proliferation. According to the distribution of $\mathrm{GI}_{50}$ value of the cell lines, leukemia cell lines were generally more sensitive than other cell lines. Therefore, K562 leukemia cells (September 2012 release) were selected as the study material and its activity data were used for the next analysis. We also selected two other cancer cell lines, MCF7 and A549 (September 2014 release), to confirm the stability and effectiveness of our algorithm. The three cancer cell lines were analyzed separately.
Activity data sets of K562, MCF7, and A549 cell lines contained 47,497; 36,801; and 51,170 entries, respectively. $2 \mathrm{D}$ structures of the corresponding active compounds were extracted and linked with the activity values. The distribution of compounds' $\mathrm{GI}_{50}$ values, ranging from micromole to nanomole, was analyzed with the cumulative frequency plot (Supplementary Figure S2). 90\% of the active compounds possessed a $\mathrm{pGI}_{50}$ (the negative logarithm of $\mathrm{GI}_{50}$ values in base 10$)$ less than $6\left(\mathrm{GI}_{50} \geq 10^{-6} \mathrm{~mol} / \mathrm{L}\right)$. Therefore, compounds with $\mathrm{pGI}_{50}$ over 6 were defined as active, which included 3658, 3744 and 4646 compounds in the three data sets, respectively. Inactive compounds were discarded.

The distributions of molecular weight and AlogP (oil water distribution coefficient) of the anticancer active compounds were compared and analyzed (Supplementary Figure S3). AlogP thresholds were set to $[2,7],[-3,8]$, and $[-3,8]$ for the three cell lines, respectively. Molecular weight thresholds were set to [150, 750], [200,800], and $[200,800]$. After property filtering, 3160, 3362, and 4150 anticancer active compounds were retained for the following analysis.

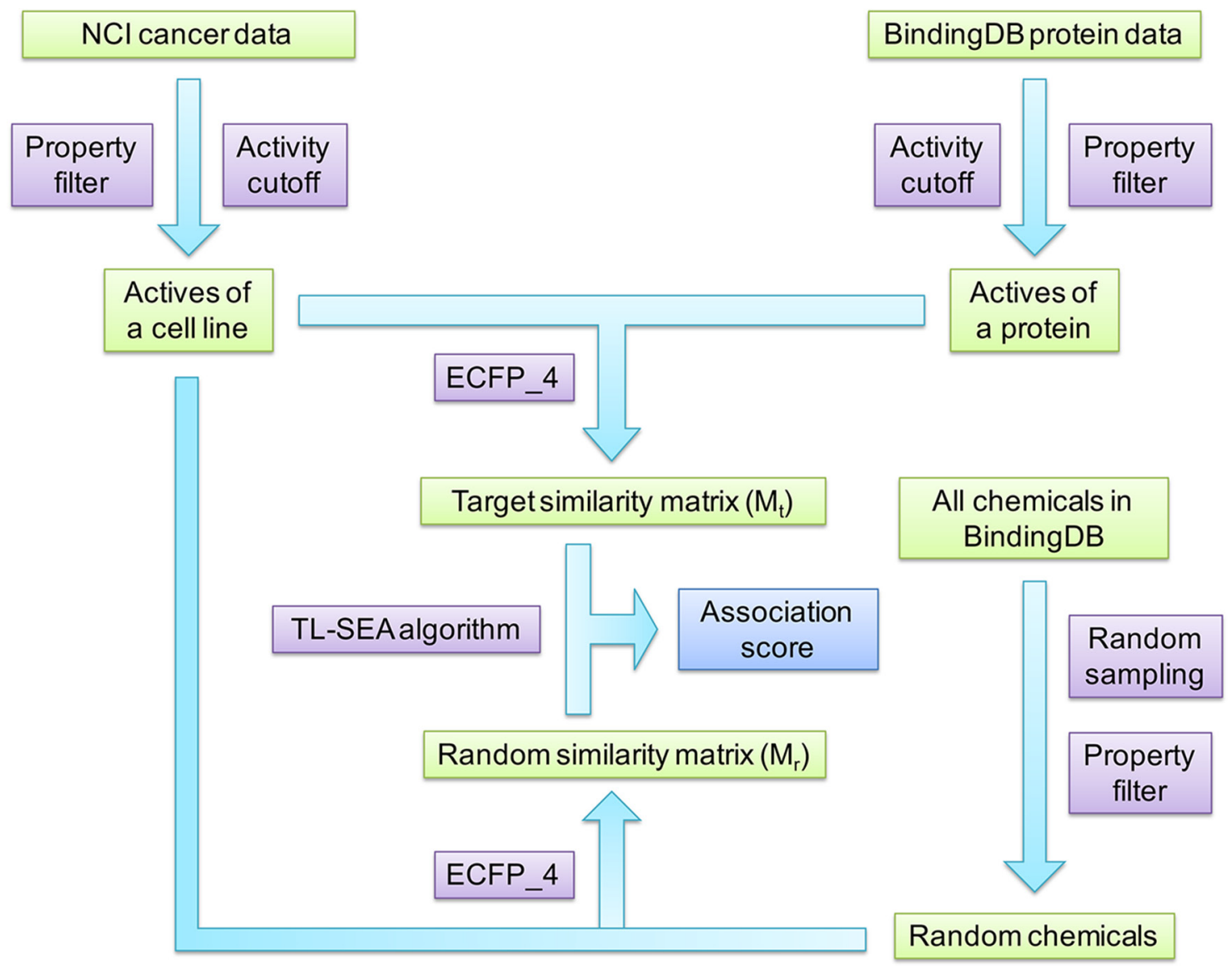

Figure 3: The overall protocol of this study. 


\section{BindingDB database}

Active data against proteins were obtained from BindingDB (http://bindingdb.org/bind/index.jsp, accessed on 2 March 2014). The binding data and 2D structures of small molecules were collected. There were four types of endpoints used in BindingDB, i.e. $K_{\mathrm{i}}, \mathrm{IC}_{50}, K_{\mathrm{d}}$ and $\mathrm{EC}_{50}$. Compounds were defined as active when any of these values were smaller than $10^{-6} \mathrm{~mol} / \mathrm{L}$. To ensure the consistency of physical and chemical properties, BindingDB compounds were also filtered with the property criteria as discussed above. The final BindingDB active ligand set contained 505,600 compounds.

\section{Generation of the similarity matrices}

A similarity matrix $(\mathrm{M})$ was generated by calculating the similarities between the NCI and BindingDB active compounds. Each column of the matrix corresponds to a NCI active compound, while each row corresponds to a BindingDB active compound. The similarity was calculated with ECFP 4 molecular fingerprint and Tanimoto coefficient. ECFP is Extended-Connectivity Fingerprints based on the Morgan algorithm [78]. It is a circular topological fingerprint designed for molecular characterization, similarity calculation, and virtual screening. The diameter of a circular atom neighborhood

All similarity matrix $(\mathrm{M})$
\begin{tabular}{|c|c|c|c|}
\hline$S_{11}$ & $S_{12}$ & $\ldots$ & $S_{1 \mathrm{n}}$ \\
\hline$S_{21}$ & $S_{22}$ & $\ldots$ & $S_{2 n}$ \\
\hline$\ldots$ & $\ldots$ & $\ldots$ & $\ldots$ \\
\hline$S_{\mathrm{m} 1}$ & $S_{\mathrm{m} 2}$ & $\ldots$ & $S_{\mathrm{mn}}$ \\
\hline
\end{tabular}
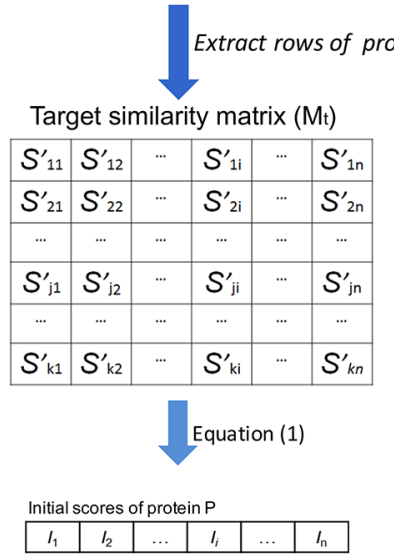

Equation (2)-(4)

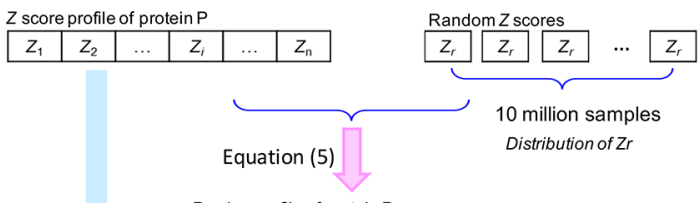

$P$-value profile of protein $\mathrm{P}$

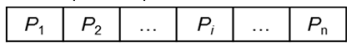

Equation (6)
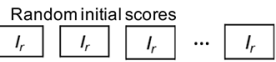
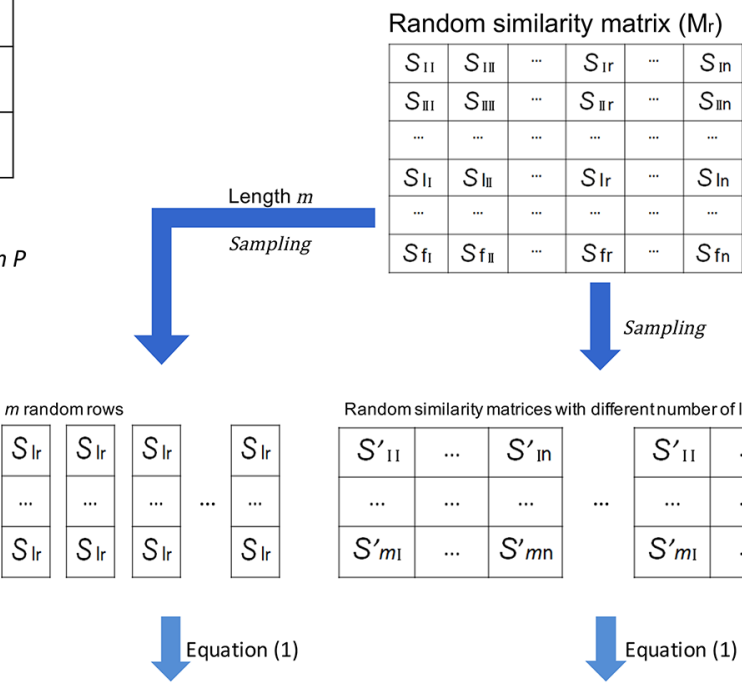

Random similarity matrices with different number of lines

\begin{tabular}{|c|c|c|c|c|c|c|}
\hline$S^{\prime}{ }_{I I}$ & ... & $S_{\text {In }}^{\prime}$ & \multirow{3}{*}{$\cdots$} & $S^{\prime}{ }_{11}$ & $\ldots$ & $S_{\text {In }}^{\prime}$ \\
\hline$\ldots$ & $\ldots$ & $\ldots$ & & $\ldots$ & $\ldots$ & $\ldots$ \\
\hline$S_{m I}^{\prime}$ & $\ldots$ & $S_{m n}^{\prime}$ & & $S_{m I}^{\prime}$ & $\ldots$ & $S_{m n}^{\prime}$ \\
\hline
\end{tabular}

Equation (1)

Initial scores of each column
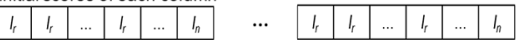

Equation (2)-(4)

$Z$ scores of each random similarity matrix

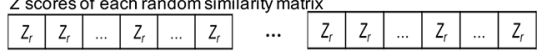

Equation (6)

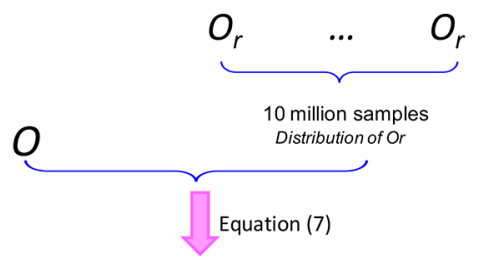

$P_{\mathrm{O}}$ (AS score)

Figure 4: Schematic representation of the TL-SEA algorithm. First, the target protein similarity matrix $\left(M_{t}\right)$ was extracted from the overall NCI-BindingDB similarity matrix (M). Then, the matrix was translated into an initial score vector. Next, the initial score vector was normalized to the $\mathrm{Z}$ score vector through random column sampling. Finally, the association score (AS) was calculated based on the $\mathrm{Z}$ score vector and another random sampling of random similarity matrixes. Here, $\mathrm{n}$ is the number of the active compounds of a NCI cell line. $\mathrm{S}$ and $\mathrm{S}$ ' are the similarity value between NCI compound and BindingDB compound. I is the sum of the similarity values over 0.15 in the corresponding column. Refer to the text for a detailed description. 
is set to 4. Tanimoto coefficient $\left(S_{\mathrm{t}}\right)$ is one of the most widely used similarity indices and is defined as $S_{\mathrm{t}}=\mathrm{C} /$ $(\mathrm{A}+\mathrm{B}-\mathrm{C})$. Here, $\mathrm{A}$ and $\mathrm{B}$ are the numbers of fingerprint bits of molecules $\mathrm{A}$ and $\mathrm{B}$, and $\mathrm{C}$ is the number of bits coexisting in both molecules.

As background sampling, around 50,000 compounds were randomly selected from BindingDB. The compounds were filtered using physicochemical properties as described above. Similarity matrices of the randomly selected BindingDB compounds against all NCI active compounds of each cell line $\left(\mathrm{M}_{\mathrm{r}}\right)$ were also calculated. Three random compound sets (similarity matrices) were prepared with different property thresholds for the three NCI cell lines.

\section{Calculating association scores using the TL-SEA algorithm}

The similarity between two unrelated compound sets was usually very weak. Therefore, a sensitive association recognition algorithm with careful statistical inference was required to predict cancer-related proteins. This algorithm needed to be able to find out the implicit association of cancer cells with particular proteins using their active molecules. Based on the SEA algorithm, which was originally proposed by Keiser [19], we proposed an improved two-layer approach (TL-SEA). The protocol of this algorithm is described as follows (Figure 4).

\section{Extract the row vectors corresponding to a BindingDB protein active set}

To analyze the association between the NCI cell line and a certain protein, the row similarity vectors corresponding to the protein's active compounds were extracted from $\mathrm{M}$. The extracted row vectors composed a target sub-matrix $\left(\mathrm{M}_{\mathrm{t}}\right)$. Proteins with less than 10 active compounds (vectors) were discarded.

Translate the similarity matrix $M_{t}$ into an initial score (I) vector by adding up all the similarity values over a threshold in each column

The frequency histograms of the random similarity values (in $\mathrm{M}_{\mathrm{r}}$ ) were analyzed and shown in Supplementary Figure S4. By analyzing the distribution of random similarity values in the random similarity matrices, we chose 0.15 as the threshold and used it to filter off weak similarity noise.

Then, by summing up all the similarity values over 0.15 in each column (NCI active compound $i$ ), the similarity matrix $\left(\mathrm{M}_{\mathrm{t}}\right)$ was translated in to a row vector. The element of the vector was defined as the initial score $(I)$ between the protein and a particular anticancer compound.

$$
I_{i}=\Sigma S_{j i}\left(S_{j i}>0.15\right)
$$

Here, the summation was made over all the similarities between the active compounds against the protein $(j)$ and the anticancer compound.
Translate the initial score vector into significance score $\left(\boldsymbol{P}_{\mathrm{Z}}\right)$

The initial score reflected the association between each protein and the corresponding anticancer compound. However, the initial score varied when the number of active compounds changed. For proteins with more active compounds, their initial scores were generally higher than proteins with less active compounds. Therefore, the initial score was translated into a comparable standardized score $(Z)$ and significance score $\left(P_{\mathrm{Z}}\right)$. This was achieved with row sampling and linear regression.

a) Random sampling was conducted against all columns in the random similarity matrix $\left(\mathrm{M}_{\mathrm{r}}\right)$. For each randomly selected column, the sampling was performed with 2000 different lengths $(m)$. The lengths were randomly selected from 1 to 10,000 . The operation was repeated for 5000 times, which produced 10 million random compound sets.

b) As we did in step 2, for each sampling, an initial score vector was obtained by summing up the similarity values larger than the threshold (0.15). Then, the distribution of the initial score over different sampling length $(m)$ was obtained through analysis of the 10 million similarity sets $(2000 \times 5000)$. Here we used the same protocol to Keiser's [19]. First, by fitting the distribution pattern over sampling length with the following equations, constants $(a, b$ and $k$ ) were obtained.

$$
\begin{aligned}
& \mu_{m}=k \times m \\
& \sigma_{m}=a \times m^{b}
\end{aligned}
$$

Here, $\mu_{m}$ and $\sigma_{m}$ are the mean and the standard deviation of $I$ in each group with sampling length $m$. $a$, $b, k$ are the constants of the distribution of $I$ in different length $m$. Then, a standardized score $(Z)$ for each initial score was calculated with the following formula:

$$
Z=(I-\hat{k} \times m) /\left(\hat{a} \times m^{\hat{b}}\right)
$$

Here, $\hat{a}, \hat{b}, \hat{k}$, are the estimated values for $a$, $b$ and $k$. The standardized score $(Z)$ was comparable between proteins with different numbers of active compounds. Finally, the standard score was translated into a significance score $\left(P_{Z}\right)$ with the formula,

$$
P_{\mathrm{Z}}=N\left(Z_{r} \geq Z_{i}\right) / N\left(Z_{r}\right)
$$

Here, $N\left(Z_{\mathrm{r}}\right)$ is the total number of $Z$ scores of the random sampling, which is equal to $10^{7} . Z_{\mathrm{i}}$ is the standardized score of the th column in the target similarity matrix of protein $\left(\mathrm{M}_{\mathrm{t}}\right) . N\left(Z_{\mathrm{r}} \geq Z_{\mathrm{i}}\right)$ is the number of $Z_{\mathrm{r}}$ which exceeds or equal $Z_{\mathrm{i}} . P_{\mathrm{Z}}$ is the statistical significance of the $i$ th column, which is equal to the probability of getting a $Z$ score no smaller than $Z_{\mathrm{i}}$ from random sampling. Therefore, the association between a cell line active compound and a certain protein can be estimated with $P_{\mathrm{Z}}$ 


\section{Translate the standardized score $(Z)$ vector into the association score $\left(\boldsymbol{P}_{\mathrm{o}}\right)$}

In the above steps, we compared the active compounds against specific proteins and each cell lines active compounds, producing the $Z$ score rating the relationship of this protein to every anticancer compound. To analyze the association between the protein and the cell line, the $Z$ score vectors were merged into a comparable association score based on random row sampling.

First, a threshold (c) of $Z$ corresponding to an acceptable confidence level (probability $P_{\mathrm{z}}=0.01$ ) was determined. By summing up the $Z$ values not less than $c$, the original association score $(O)$ of a certain protein was obtained.

$$
O=\Sigma Z \quad(Z \geq c)
$$

Then, random rows were extracted from the random similarity matrix $\left(\mathrm{M}_{\mathrm{r}}\right)$. Similarly to the last step, the matrix sampling was performed with 2000 different numbers and repeated for 5000 times for each number. This sampling formed 10 million sub-matrices in total. For each matrix, the initial score and $Z$ score of each column were calculated as previously described. And, the original score $\left(O_{\mathrm{r}}\right)$ of random selected compounds was calculated. There were 10 million $O_{\mathrm{r}}$ values in total.

Because every original score $(O)$ was calculated in the same length that was equal to the number of active compounds against the cell line, it was unnecessary to standardize this value. The significance of the original score, here defined as the association score (AS score, $P_{\mathrm{O}}$ ), was calculated as the probability of getting an random $O_{\mathrm{r}}$ that is not less than $O$ score in random sampling.

$$
P_{\mathrm{O}}=N\left(O_{\mathrm{r}} \geq O\right) / N\left(O_{\mathrm{r}}\right)
$$

$N\left(O_{\mathrm{r}} \geq O\right)$ denotes the number of $O_{\mathrm{r}}$ which exceeds or equals $O$, and $N(O)$ indicates the total number of $O$ (10 million). This final association score (AS or $P_{\mathrm{O}}$ ) reflects whether the protein has a function in proliferation, apoptosis, or differentiation of cancer cells.

Molecular property and similarity calculation and automatic data processing were performed with Pipeline Pilot (version 8.5). The TL-SEA algorithm was implemented with a MATLAB script $(7.14,2012 a)$.

\section{Protein-compound association networks}

During the process of AS score $\left(P_{\mathrm{O}}\right)$ calculation, a $P$-value $\left(P_{\mathrm{z}}\right)$ matrix between the NCI compounds and the BindingDB proteins was formed. For matrix elements with very low $P_{\mathrm{z}}$ value, there was a great chance that the corresponding NCI compound and the protein can bind to each other. To illustrate the relationships between NCI chemicals and BindingDB proteins clearly, we retained the matrix elements with $P_{\mathrm{Z}}$ lower than 0.0001 and converted the matrix into a chemical-protein interaction network. The network was graphically presented, rendered with Cytoscape [79] (version 2.8.2) by Force-Directed BioLayout. The edge was weighted by the reciprocal of the negative of the common logarithm of $P_{\mathrm{Z}}$.

\section{ACKNOWLEDGMENTS AND FUNDING}

This work was supported by the Fundamental Research Funds for the Central Universities (2662014PY007) and the National Natural Science Foundation of China (21075046, 21275061). The funders had no role in study design, data collection and analysis, decision to publish, or preparation of the manuscript.

\section{CONFLICTS OF INTEREST}

The authors declare no competing financial interests.

\section{REFERENCES}

1. Lozano R, Naghavi M, Foreman K, Lim S, Shibuya K, Aboyans V, Abraham J, Adair T, Aggarwal R, Ahn SY, Alvarado M, Anderson HR, Anderson LM, et al. Global and regional mortality from 235 causes of death for 20 age groups in 1990 and 2010: a systematic analysis for the Global Burden of Disease Study 2010. Lancet. 2012; 380:2095-2128.

2. Jemal A, Bray F, Center MM, Ferlay J, Ward E, Forman D. Global cancer statistics. CA Cancer J Clin. 2011; 61:69-90.

3. Sawyers C. Targeted cancer therapy. Nature. 2004; 432:294-297.

4. Hanahan D, Weinberg RA. Hallmarks of cancer: the next generation. Cell. 2011; 144:646-674.

5. Stratton MR. Exploring the genomes of cancer cells: progress and promise. Science. 2011; 331:1553-1558.

6. Shah K, Bradbury NA. Lemur Tyrosine Kinase 2, a novel target in prostate cancer therapy. Oncotarget. 2015; 6:14233-14246. doi: 10.18632/oncotarget.3899.

7. Whitworth H, Bhadel S, Ivey M, Conaway M, Spencer A, Hernan R, Holemon H, Gioeli D. Identification of kinases regulating prostate cancer cell growth using an RNAi phenotypic screen. PloS one. 2012; 7: e38950.

8. Culig Z, Bartsch G, Hobisch A. Interleukin-6 regulates androgen receptor activity and prostate cancer cell growth. Mol Cell Endocrinol. 2002; 197:231-238.

9. Huang $\mathrm{CH}$, Peng HS. Prediction of cancer proteins by integrating protein interaction, domain frequency, and domain interaction data using machine learning algorithms. 2015; 2015:312047.

10. Tao C, Sun J, Zheng WJ, Chen J, Xu H. Colorectal cancer drug target prediction using ontology-based inference and network analysis. Database : the journal of biological databases and curation. 2015; 2015: bav015. 
11. Huang C, Ba Q, Yue Q, Li J, Li J, Chu R, Wang H. Artemisinin rewires the protein interaction network in cancer cells: network analysis, pathway identification, and target prediction. Molecular bioSystems. 2013; 9: 3091-3100.

12. Monks A, Scudiero D, Skehan P, Shoemaker R, Paull K, Vistica D, Hose C, Langley J, Cronise P, Vaigro-Wolff A. Feasibility of a high-flux anticancer drug screen using a diverse panel of cultured human tumor cell lines. J Natl Cancer Inst. 1991; 83:757-766.

13. Liu T, Lin Y, Wen X, Jorissen RN, Gilson MK. BindingDB: a web-accessible database of experimentally determined protein-ligand binding affinities. Nucleic Acids Res. 2007; 35: D198-201.

14. Gedeck P, Lewis RA. Exploiting QSAR models in lead optimization. Curr Opin Drug Discov Devel. 2008; 11: 569-575.

15. Martin YC, Kofron JL, Traphagen LM. Do structurally similar molecules have similar biological activity? J Med Chem. 2002; 45:4350-4358.

16. Schuffenhauer A, Floersheim P, Acklin P, Jacoby E. Similarity metrics for ligands reflecting the similarity of the target proteins. J Chem Inf Comput Sci. 2003; 43:391-405.

17. Vilar S, Cozza G, Moro S. Medicinal chemistry and the molecular operating environment (MOE): application of QSAR and molecular docking to drug discovery. Curr Top Med Chem. 2008; 8:1555-1572.

18. Vilar S, Santana L, Uriarte E. Probabilistic neural network model for the in silico evaluation of anti-HIV activity and mechanism of action. J Med Chem. 2006; 49:1118-1124.

19. Keiser MJ, Roth BL, Armbruster BN, Ernsberger P, Irwin JJ, Shoichet BK. Relating protein pharmacology by ligand chemistry. Nat Biotechnol. 2007; 25:197-206.

20. Hert J, Keiser MJ, Irwin JJ, Oprea TI, Shoichet BK. Quantifying the relationships among drug classes. Journal of chemical information and modeling. 2008; 48:755-765.

21. Yee SW, Lin L, Merski M, Keiser MJ, Gupta A, Zhang Y, Chien HC, Shoichet BK, Giacomini KM. Prediction and validation of enzyme and transporter offtargets for metformin. Journal of pharmacokinetics and pharmacodynamics. 2015; 42:755-765.

22. Lozzio BB, Lozzio CB. Properties and usefulness of the original K-562 human myelogenous leukemia cell line. Leuk Res. 1979; 3:363-370.

23. Zamfir Chiru AA, Popescu CR, Gheorghe DC. Melatonin and cancer. Journal of medicine and life. 2014; 7:373-374.

24. Lin FY, Lin CW, Yang SF, Lee WJ, Lin YW, Lee LM, Chang JL, Weng WC, Lin CH, Chien MH. Interactions between environmental factors and melatonin receptor type 1A polymorphism in relation to oral cancer susceptibility and clinicopathologic development. PloS one. 2015; 10: e0121677.

25. Jablonska K, Pula B, Zemla A, Kobierzycki C, Kedzia W, Nowak-Markwitz E, Spaczynski M, Zabel M, Podhorska-
Okolow M, Dziegiel P. Expression of the MT1 melatonin receptor in ovarian cancer cells. International journal of molecular sciences. 2014; 15:23074-23089.

26. Reppert SM, Weaver DR, Ebisawa T. Cloning and characterization of a mammalian melatonin receptor that mediates reproductive and circadian responses. Neuron. 1994; 13:1175-1185.

27. Maestroni GJ. The immunotherapeutic potential of melatonin. Expert Opin Investig Drugs. 2001; 10:467-476.

28. Mao L, Yuan L, Slakey LM, Jones FE, Burow ME, Hill SM. Inhibition of breast cancer cell invasion by melatonin is mediated through regulation of the p38 mitogen-activated protein kinase signaling pathway. Breast Cancer Res. 2010; 12: R107.

29. Slominski RM, Reiter RJ, Schlabritz-Loutsevitch N, Ostrom RS, Slominski AT. Melatonin membrane receptors in peripheral tissues: distribution and functions. Mol Cell Endocrinol. 2012; 351:152-166.

30. Sauer LA, Dauchy RT, Blask DE. Melatonin inhibits fatty acid transport in inguinal fat pads of hepatoma 7288CTCbearing and normal Buffalo rats via receptor-mediated signal transduction. Life Sci. 2001; 68:2835-2844.

31. Toma CD, Svoboda M, Arrich F, Ekmekcioglu C, Assadian O, Thalhammer T. Expression of the melatonin receptor (MT) 1 in benign and malignant human bone tumors. J Pineal Res. 2007; 43:206-213.

32. Xu L, Liu H, Zhang H, Wang RX, Song J, Song J, Zhou RX. Growth-inhibitory activity of melatonin on murine foregastric carcinoma cells in vitro and the underlying molecular mechanism. Anat Rec (Hoboken). 2013; 296:914-920.

33. Risinger AL, Giles Fj, Mooberry SL. Microtubule dynamics as a target in oncology. Cancer Treat Rev. 2009; 35: 255-261.

34. Jordan MA, Wilson L. Microtubules as a target for anticancer drugs. Nat Rev Cancer. 2004; 4:253-265.

35. Kocaturk B, Versteeg HH. Tissue factor isoforms in cancer and coagulation: may the best isoform win. Thromb Res. 2012; 129: S69-S75.

36. Schaffner F, Yokota N, Ruf W. Tissue factor proangiogenic signaling in cancer progression. Thromb Res. 2012; 129: S127-S31.

37. Versteeg HH, Spek CA, Peppelenbosch MP, Richel DJ. Tissue factor and cancer metastasis: the role of intracellular and extracellular signaling pathways. Mol Med. 2004; 10:6-11.

38. Yu JL, May L, Lhotak V, Shahrzad S, Shirasawa S, Weitz JI, Coomber Bl, Mackman N, Rak JW. Oncogenic events regulate tissue factor expression in colorectal cancer cells: implications for tumor progression and angiogenesis. Blood. 2005; 105:1734-1741.

39. Xu C, Gui Q, Chen W, Wu L, Sun W, Zhang N, Xu Q, Wang J, Fu X. Small interference RNA targeting tissue 
factor inhibits human lung adenocarcinoma growth in vitro and in vivo. J Exp Clin Cancer Res. 2011; 30:63.

40. Milsom C, Rak J. Tissue factor and cancer. Pathophysiol Haemost Thromb. 2008; 36:160-176.

41. Ruf W. Tissue factor and PAR signaling in tumor progression. Thromb Res. 2012; 130: S84-S87.

42. Soderling SH, Bayuga SJ, Beavo JA. Isolation and characterization of a dual-substrate phosphodiesterase gene family: PDE10A. Proceedings of the National Academy of Sciences of the United States of America. 1999; 96: 7071-7076.

43. Dong H, Claffey KP, Brocke S, Epstein PM. Inhibition of breast cancer cell migration by activation of cAMP signaling. Breast cancer research and treatment. 2015; 152:17-28.

44. Calebiro D, Di Dalmazi G, Bathon K, Ronchi CL, Beuschlein F. cAMP signaling in cortisol-producing adrenal adenoma. European journal of endocrinology. 2015; 173: m99-m106.

45. Gougoumas DD, Vizirianakis IS, Triviai IN, Tsiftsoglou AS. Activation of Prn-p gene and stable transfection of Prn-p cDNA in leukemia MEL and neuroblastoma N2a cells increased production of $\operatorname{PrP}(\mathrm{C})$ but not prevented DNA fragmentation initiated by serum deprivation. J Cell Physiol. 2007; 211:551-559.

46. Diarra Mehrpour M, Arrabal S, Jalil A, Pinson X, Gaudin C, Pietu G, Pitaval A, Ripoche H, Eloit M, Dormont D, Chouaib S. Prion protein prevents human breasr carcinoma cell line from tumor necrosis factor alpha-induced cell death. Cancer Res. 2004; 64:719-727.

47. Muras AG, Hajj GN, Ribeiro KB, Nomizo R, Nonogaki S, Chammas R, Martins VR. Prion protein ablation increases cellular aggregation and embilization contributing to mechanisms of metastasis. Int J Cancer. 2009; 125: 1523-1531.

48. Rubal JJ, Moreno-Dorado FJ, Guerra FM, Jorge ZD, Galan Mdel C, Salido GM, Christensen SB, Sohoel H, Massanet GM. A phenylpropanoid, a slovenolide, two sulphur-containing germacranes and Ca2+-ATPase inhibitors from Thapsia villosa. Planta medica. 2010; 76:284-290.

49. Kusuhara M, Yamaguchi K, Nagasaki K, Hayashi C, Suzaki A, Hori S, Handa S, Nakamura Y, Abe K. Production of endothelin in human cancer cell lines. Cancer Res. 1990; 50:3257-3261.

50. Wulfing P, Diallo R, Kersting C, Wulfing C, Poremba C, Rody A, Greb RR, Bocker W, Kiesel L. Expression of endothelin-1, endothelin-A, and endothelin-B receptor in human breast cancer and correlation with long-term follow- up. Clin Cancer Res. 2003; 9:4125-4131.

51. Li Q, Cheng T, Wang Y, Bryant SH. PubChem as a public resource for drug discovery. Drug discovery today. 2010; 15:1052-1057.
52. Gaulton A, Bellis LJ, Bento AP, Chambers J, Davies M, Hersey A, Light Y, McGlinchey S, Michalovich D, Al-Lazikani B, Overington JP. ChEMBL: a large-scale bioactivity database for drug discovery. Nucleic Acids Res. 2012; 40: D1100-1107.

53. Santoro R, Mori F, Marani M, Grasso G, Cambria MA, Blandino G, Muti P, Strano S. Blockage of melatonin receptors impairs p53-mediated prevention of DNA damage accumulation. Carcinogenesis. 2013; 34:1051-1061.

54. Grzanka A, Grzanka D, Orlikowska M. Cytoskeletal reorganization during process of apoptosis induced by cytostatic drugs in K-562 and HL-60 leukemia cell lines. Biochem Pharmacol. 2003; 66:1611-1617.

55. Kocaturk B, Van den Berg YW, Tieken C, Mieog JS, de Kruijf EM, Engels CC, van der Ent MA, Kuppen PJ, Van de Velde CJ, Ruf W, Reitsma PH, Osanto S, Liefers GJ, et al. Alternatively spliced tissue factor promotes breast cancer growth in a betal integrin-dependent manner. Proceedings of the National Academy of Sciences of the United States of America. 2013; 110:11517-11522.

56. Tarnowski M, Liu R, Wysoczynski M, Ratajczak J, Kucia M, Ratajczak MZ. CXCR7: a new SDF-1-binding receptor in contrast to normal $\mathrm{CD} 34(+)$ progenitors is functional and is expressed at higher level in human malignant hematopoietic cells. Eur J Haematol. 2010; $85: 472-483$.

57. Zahner G, Wolf G, Ayoub M, Reinking R, Panzer U, Shankland SJ, Stahl RA. Cyclooxygenase-2 overexpression inhibits platelet-derived growth factor-induced mesangial cell proliferation through induction of the tumor suppressor gene p53 and the cyclin-dependent kinase inhibitors p21waf-1/cip-1 and p27kip-1. J Biol Chem. 2002; 277:9763-9771.

58. Abdelhaleem M. Do human RNA helicases have a role in cancer? Biochim Biophys Acta. 2004; 1704:37-46.

59. Xu Z, Shi H, Mei Q, Shen Y, Xu J. Effects of macrophage metalloelastase on the basic fibroblast growth factor expression and tumor angiogenesis in murine colon cancer. Digestive diseases and sciences. 2012; 57:85-91.

60. Canta A, Chiorazzi A, Cavaletti G. Tubulin: a target for antineoplastic drugs into the cancer cells but also in the peripheral nervous system. Curr Med Chem. 2009; 16:1315-1324.

61. Bigioni M, Benzo A, Irrissuto C, Maggi CA, Goso C. Role of NK-1 and NK-2 tachykinin receptor antagonism on the growth of human breast carcinoma cell line MDA-MB-231. Anticancer Drugs. 2005; 16:1083-1089.

62. Kimura Y, Morita SY, Matsuo M, Ueda K. Mechanism of multidrug recognition by MDR1/ABCB1. Cancer science. 2007; 98:1303-1310.

63. Wang S, Yang Q, Fung KM, Lin HK. AKR1C2 and AKR1C3 mediated prostaglandin D2 metabolism augments the PI3K/Akt proliferative signaling pathway in human prostate cancer cells. Mol Cell Endocrinol. 2008; 289: $60-66$. 
64. Lacoste C, Herve J, Bou Nader M, Dos Santos A, Moniaux N, Valogne Y, Montjean R, Dorseuil O, Samuel D, Cassio D, Portulano C, Carrasco N, Brechot C, et al. Iodide transporter NIS regulates cancer cell motility and invasiveness by interacting with the Rho guanine nucleotide exchange factor LARG. Cancer research. 2012; 72:5505-5515.

65. Sheng WY, Yong Z, Yun Z, Hong H, Hai LL. Toll-like receptor 4 gene polymorphisms and susceptibility to colorectal cancer: a meta-analysis and review. Archives of medical science : AMS. 2015; 11:699-707.

66. Nakamachi T, Sugiyama K, Watanabe J, Imai N, Kagami N, Hori M, Arata S, Shioda S. Comparison of expression and proliferative effect of pituitary adenylate cyclaseactivating polypeptide (PACAP) and its receptors on human astrocytoma cell lines. Journal of molecular neuroscience. 2014; 54:388-394.

67. Xie G and Raufman JP. Role of the Aryl Hydrocarbon Receptor in Colon Neoplasia. Cancers. 2015; 7:1436-1446.

68. Salyer SA, Olberding JR, Distler AA, Lederer ED, Clark BJ, Delamere NA, Khundmiri SJ. Vacuolar ATPase driven potassium transport in highly metastatic breast cancer cells. Biochim Biophys Acta. 2013; 1832:1734-1743.

69. Bloch M, Ousingsawat J, Simon R, Schraml P, Gasser TC, Mihatsch MJ, Kunzelmann K, Bubendorf L. KCNMA1 gene amplification promotes tumor cell proliferation in human prostate cancer. Oncogene. 2007; 26:2525-2534.

70. Li F, Fei X, Xu J, Ji C. An unannotated alpha/beta hydrolase superfamily member, ABHD6 differentially expressed among cancer cell lines. Molecular biology reports. 2009; 36:691-696.

71. Kim DG, Jin Y, Jin J, Yang H, Joo KM, Lee WS, Shim SR, Kim SW, Yoo J, Lee SH, Yoo JS, Nam DH. Anticancer activity of TTAC-0001, a fully human anti-vascular endothelial growth factor receptor 2 (VEGFR-2/KDR) monoclonal antibody, is associated with inhibition of tumor angiogenesis. mAbs. 2015; 7:1195-1024.
72. Wang JR, Li XH, Gao XJ, An SC, Liu H, Liang J, Zhang K, Liu Z, Wang J, Chen Z, Sun W. Expression of MMP-13 is associated with invasion and metastasis of papillary thyroid carcinoma. European review for medical and pharmacological sciences. 2013; 17:427-435.

73. Monnier J, Samson M. Prokineticins in angiogenesis and cancer. Cancer Lett. 2010; 296:144-149.

74. Andreis PG, Rucinski M, Neri G, Conconi MT, Petrelli L, Parnigotto PP, Malendowicz LK and Nussdorfer GG. Neuropeptides B and W enhance the growth of human adrenocortical carcinoma-derived NCI-H295 cells by exerting MAPK p42/p44-mediated proliferogenic and antiapoptotic effects. Int J Mol Med. 2005; 16:1021-1028.

75. Levy I, Horvath A, Azevedo M, de Alexandre RB, Stratakis CA. Phosphodiesterase function and endocrine cells: links to human disease and roles in tumor development and treatment. Curr Opin Pharmacol. 2011; 11:689-697.

76. Wittau N, Grosse R, Kalkbrenner F, Gohla A, Schultz G, Gudermann T. The galanin receptor type 2 initiates multiple signaling pathways in small cell lung cancer cells by coupling to G(q), G(i) and G(12) proteins. Oncogene. 2000; 19:4199-4209.

77. Apweiler R, Bairoch A, Wu CH, Barker WC, Boeckmann B, Ferro S, Gasteiger E, Huang H, Lopez R, Magrane M, Martin MJ, Natale DA, O'Donovan C, et al. UniProt: the Universal Protein knowledgebase. Nucleic Acids Res. 2004; 32: D115-119.

78. Cereto-Massague A, Ojeda MJ, Valls C, Mulero M, GarciaVallve S, Pujadas G. Molecular fingerprint similarity search in virtual screening. Methods (San Diego, Calif). 2015; 71:58-63.

79. Smoot ME, Ono K, Ruscheinski J, Wang PL, Ideker T. Cytoscape 2.8: new features for data integration and network visualization. Bioinformatics (Oxford, England). $2011 ; 27: 431-432$. 